\title{
Preparation of a composite mix from local indigenous crops
}

Keywords: nutritional, benefits, composite, achieved, materials, ingredients, markets, raw, health, particles

\section{Opinion}

In a recent work carried out by four student's viz. Neelabh, Shikhar, Saurav and Shibali under the supervision of Dr. Komal Chauhan, Asst. Professor at National Institute of Food Technology Entrepreneurship and Management [NIFTEM], Kundli, Sonepat, Haryana, INDIA it was concluded that several health and nutritional benefits could be achieved from a product made from a composite mix. Different ingredients and raw materials were procured from local markets of Haryana and Delhi. Its health benefits and nutritional information were studied carefully.

Different ingredients and raw materials procured were:

a. Cereals and Millets

A. Rice (Oryza sativa)

B. Wheat ( Triticum aestivum)

C. Ragi (Eleusine coracana)

I. Pulses

A. Puffed Bengal Gram ( Cicer arietinum )

B. Defatted soya flour ( Glycine max Merr )

II. Nuts and Oilseeds

A. Almond ( Prunus dulcis)

B. Cashew nut (Anacardium occidentale)

C. Ground nut (Arachis hypogaea)

D. Flax Seed ( Linum usitatissimum )

The above ingredients were roasted and grinded carefully by removing all foreign particles. It was then mixed in different proportions and a mix was prepared. The mix was then used to make different products by different methods viz. by baking, frying and fermenting. Product range include: toast, pan cake, savory, muruku etc.

The composite mix is rich in carbohydrate, protein, fibre, vitamins
Volume 4 Issue 4 - 2017

\author{
Neelabh Utkarsh \\ Department of Food Technology and Management, National \\ Institute of Food Technology Entrepreneurship and Management \\ (NIFTEM), India \\ Correspondence: Neelabh Utkarsh, B.Tech in Food \\ Technology and Management, National Institute of Food \\ Technology Entrepreneurship and Management (NIFTEM), B-12, \\ Sheetal Kunj Flat, Nirala Nagar, Shivpurwa,Varanasi-221010, \\ Uttar Pradesh, India, Tel +91-8395910374, \\ Email neelabh.utkarsh@gmail.com \\ Received: June 20, 2016 | Published: May II, 2017
}

and antioxidants. Several health benefits served are prevention from cancer, osteoporosis, arthritis, diabetes, Alzheimer's disease etc. Bioactive compounds like isoflavones, saponins, phytic acid, polyphenols, phytochemicals etc. prevents from several chronic and carcinogenic diseases.

Wheat grass and barley grass powder could also be added so as to make the mix richer in antioxidants. By this every human could have a rich nutritional diet and also could be able to have a protective shield against the diseases which could lead to depressing and low-thinking life.

By using these type of mixes in day to day to products like chapatti and different home made products people could make their life healthier and happier. Consumption of these products would also help in strong gut and would minimize several stomach related problems. Human health would be preserved and would also lead to lesser medical treatments.

\section{Acknowledgements}

None.

\section{Conflict of interest}

The author declares no conflict of interest. 